\title{
IMPACTOS DO PENSAMENTO PÓS-FORMAL NA ADMINISTRAÇÃO SEGUNDO A TEORIA DA COMPETITIVIDADE
}

\section{Vagner José Oliva*}

RESUMO: O impacto que o pensamento pós-formal acarreta na sociedade é analisado sob as luzes da teoria sobre campos e armas da competição (abordando apenas preço e qualidade) e considerando o diferente estágio competitivo das empresas de serviços em relação às industriais e os pontos de vista da empresa e do consumidor. Em tal contexto, cinco impactos considerados mais importantes são focalizados.

\section{Pós-formal ou pós-tudo?}

A Teoria Geral da Administração, que na verdade comporta diversas teorias, podia ser entendida por meio de duas grandes linhas, a formal e a comportamental, que acabaram por fundir-se.

A linha formalista, tomando Idalberto Chiavenato como referência, está consubstanciada na Administração Científica (Taylor), na Teoria Clássica, na Teoria Neoclássica e na Teoria da Burocracia (Weber) (Chiavenato, 1983). A linha comportamentalista está consubstanciada na Teoria das Relações Humanas, na Teoria do Comportamento Administrativo e na Teoria do Desenvolvimento Organizacional.

A Teoria Estruturalista começou a fundir essas duas linhas numa só, como mostra José Luiz Contador (1999) em Abordagens da Administração na Organização. E a Teoria dos Sistemas aplicada à Administração, principalmente a Teoria dos Sistemas Sociotécnicos, e a Teoria da Contingência passaram a não mais distinguir a linha formal da comportamentalista -tratam a empresa simultaneamente pelos dois enfoques, o que pode ser batizado de linha sociotécnica.

Difícil fica, portanto, definir o que é pensamento pós-formal em Administração. Pode ser tanto o comportamentalista como o sociotécnico, pois ambos surgiram após o formal. Entretanto, seria mais interessante, pelo nosso ponto de
PALAVRAS-CHAVE: pensamento pós-formal, campos e armas da competição, empresas, consumidor, industriais

\begin{abstract}
*Livre-docente pela Universidade Estadual Paulista - UNESP e seu Pró-Reitor de Extensão Universitária e Assuntos Comunitários (1993-1997). Atualmente é membro do Conselho Estadual de Educação de São Paulo e Coordenador do Mestrado em Administração do Centro Universitário Nove de Julho - UNINOVE.
\end{abstract}


vista, abordar o tema segundo a mais recente teoria da Administração - a Teoria da Competitividade, que ainda está em formação.

\section{Teoria da Competitividade: campos e armas da competição}

A Teoria da Competitividade estuda as formas de a empresa competir no mundo atual, principalmente abordando o enfoque estratégico. Está aqui a origem da confusão entre competitividade e estratégia, confusão que é resolvida pelo uso da expressão estratégia competitiva, consagrada por Michael Porter (Porter, 1989).

Parece-nos bastante adequado tratar o tema deste artigo segundo o enfoque de José Celso Contador, pela objetividade da forma como estuda a competitividade empresarial: concentra-se o autor na análise dos campos da competição e das armas da competição, tanto em Modelo para Aumentar a Competitividade Industrial (Contador, 1996), como em A Empresa do Futuro (Contador, 1998).

Campo da competição diz respeito a um atributo do interesse do comprador, como preço, qualidade, prazo de entrega (quinze campos são os apontados por Celso Contador). Armas da competição são os meios que a empresa utiliza para alcançar vantagem competitiva num determinado "campo", como produtividade, qualidade no processo, rapidez na produção (mais de uma centena de "armas" são apontadas pelo autor). Assim, convém analisar, neste artigo, os impactos sobre a sociedade acarretados pela empresa administrada segundo a Teoria da Competitividade. Obviamente, apenas os impactos mais significativos serão abordados.

\section{As empresas industriais e as de serviço estão em diferente estágio competitivo}

As empresas industriais e as de serviço estão em diferentes estágios de desenvolvimento administrativo e em diferentes estágios competitivos. A industrial vem sendo estruturada, reestruturada, organizada, reorganizada há cem anos; possui uma tradição de cem anos que a leva a preocupar-se com os aspectos administrativos. Esse processo na de serviço é muito mais recente, de apenas duas décadas 
- os bancos, os supermercados, as cadeias de fast food só muito recentemente estão usando palavras como produtividade e qualidade, conceitos centenários dentro da indústria; escolas, hospitais e restaurantes, mesmo os de grande porte, ainda não entraram decisivamente nessa seara.

Portanto, no aspecto competitivo, é necessário distinguir a empresa de serviço da industrial. Abordaremos, inicialmente, a competição em preço para a empresa industrial, depois para a de serviço; em seguida, a competição em qualidade para a industrial e finalmente para a de serviço. Por razão de espaço, nos restringiremos a esses dois campos da competição - preço e qualidade -, lembrando que Celso Contador analisa, como já mencionado, quinze campos da competição.

\section{Primeiro impacto:}

\section{sobre a competição em preço para as empresas industriais}

Como afirma Celso Contador (1998, p. 11):

$\mathrm{O}$ aspecto socialmente injusto do atual modelo de empresa provém do acirramento da competição em preço, inaugurada, já na década de 1950, pela política agressiva das empresas japonesas. A competição em preço sempre existiu e continuará existindo. No passado, entretanto, o decorrente ônus social era bem menor, as empresas tinham lucro que garantia sua sobrevivência e os governos não eram pressionados a subsidiar tanto e a manter o câmbio subvalorizado, políticas que penalizam toda a população.

Comparada com a de hoje, a vida na empresa era mais tranqüila há vinte anos, apesar de todas as dificuldades da época, porque, atualmente, a concorrência global cresce de intensidade dia a dia. Antes, era fácil estabelecer o preço de venda: a empresa apurava o custo total e adicionava o lucro pretendido. Hoje, o preço de venda tem outro conceito: é o preço internacional. Portanto, o lucro da empresa não é prefixado, mas é a diferença entre o preço global e o custo total. Sendo diferença, ele pode ser negativo, ou seja, prejuízo. Daí a necessidade urgente de aumentar a produtividade para reduzir custos, pois medidas do tipo corte de despesas gerais estão se exaurindo.

Após detalhada análise, Celso Contador (1998, p. 12) conclui: 
Se há uma grande insatisfação mundial com o desenvolvimento social, do qual o desemprego é apenas uma face, pressões deverão surgir na direção da mudança do modelo. Acreditamos, pois, que haverá no mundo todo um retorno aos valores do passado, e a competição em preço não será tão aguerrida.

Esta conclusão é também decorrente de outra constatação: a diminuição no ritmo do crescimento da produtividade empresarial. A redução de preço, todos sabem, provém do aumento da produtividade, que é alcançado via trabalho, por meio da organização e das metodologias mais eficientes, e via capital, por meio de tecnologias de processo mais eficientes. Ao longo da história, os incrementos na produtividade não foram lineares: há períodos de intenso incremento seguidos de períodos de incremento discreto.

As empresas industriais líderes em produtividade praticamente esgotaram a capacidade de introduzir aperfeiçoamentos que levam a incrementos significativos - estão, como é usual afirmar, mais ajustadas. Por decorrência, seus custos estão quase incompressíveis para as metodologias e tecnologias de processo atualmente disponíveis, o que as impedirá de reduzir o preço dos produtos sem comprometer a margem de lucro.

Essa análise aplica-se à produtividade do processo produtivo. Poderá haver, entretanto, significativos aumentos de produtividade em outros recursos produtivos. Um novo material, um novo projeto advindo de uma nova tecnologia embutida no produto, uma nova fonte de energia poderão aumentar rápida e expressivamente a produtividade da empresa em relação a esses recursos e diminuir o custo. Importante relembrar que o aumento proveniente desses fatores, não causando demissão de pessoal, é extremamente benéfico. Entretanto, as empresas seguidoras e as retardatárias em produtividade ainda precisam dar especial atenção à produtividade, para elevá-la a um patamar próximo ao das líderes.

Essa é a análise pelo lado da empresa. E pelo lado do cliente e do consumidor? Acreditamos que, pela ótica do cliente e do consumidor, o preço dos produtos não-monopolizados, ou seja, aqueles que possuem similares e que estão num mercado onde há concorrência verdadeira, deixará de ser um critério ganhador de pedido para se tornar um critério qualificador, pois seu valor já está num patamar que pode ser considerado justo. De acordo com Corrêa \& Gianesi (1997), critério competitivo qualificador é aquele no qual a empresa deve atingir 
um nível mínimo de desempenho que a qualificará a competir por um mercado; e critério competitivo ganhador de pedido é aquele que levará o cliente a decidir quem será o fornecedor, dentre aqueles qualificados. No caso em pauta, um preço muito abaixo do valor que o cliente está disposto a pagar não será decisivo, ou seja, não o fará decidir em favor desse produto porque será critério qualificador (uma pessoa que está disposta a pagar $\mathrm{R} \$ 40,00$ por uma camisa não comprará uma por $\mathrm{R} \$ 10,00)$. O desempenho num critério competitivo qualificador muito superior ao nível mínimo não representa vantagem competitiva.

Por esta razão, acreditamos que, no futuro, será bem mais branda a competição em preço daqueles produtos cujos preços são justos.

\section{Segundo impacto:}

\section{sobre a competição em preço para as empresas de serviços}

Ao contrário das empresas industriais, as de serviço, na maioria dos ramos, não estão acostumadas a competir em preço. Esta é a opinião, entre outras, de Horovitz (1993) e de Karl Albrecht (1994). Horovitz reconhece a existência da competição em preço, mas evidencia que as empresas preferem concorrer via diferenciação:

Em geral, as empresas francesas estão mal equipadas para ganhar uma batalha competitiva no terreno dos preços. Isso supóe poder reduzir os custos proporcionalmente. Nesse jogo em especial há sempre um concorrente capaz de fazer melhor, quer se trate de uma firma com acesso a mão-de-obra mais barata, quer de uma firma americana ou japonesa cujo mercado nacional lhe permite, graças à sua dimensão, aproveitar a curva de experiência (baixar os preços para ganhar uma parte de mercado que lhe permita produzir mais barato). Por outro lado, os preços raramente constituem uma vantagem competitiva duradoura. Mesmo no caso em que a empresa consegue desenvolver uma tecnologia radicalmente nova, ela acaba sendo alcançada pelas demais. Em compensação, as empresas francesas dispõem de uma mina de savoir-faire que lhes proporciona um trunfo considerável na batalha competitiva através da diferença. Os restaurantes, a gastronomia, a perfumaria, a alta-costura, o turismo, o lazer, a criação de softwares são áreas em que a indústria francesa soube garantir um lugar dominante nos mercados mundiais (Horovitz, 
Para demonstrar que as empresas de serviço, na maioria dos ramos, não estão acostumadas a competir em preço, Karl Albrecht (1997) compara os dois estilos:

- no estilo General Motors, a produtividade do capital e do trabalho causa lucro;

- no estilo administração de serviços, a qualidade do serviço causa lucro.

Albrecht tem razão apenas parcial na comparação, pois o estilo GM, baseado nas teorias de Taylor e Ford, não é mais utilizado na sua íntegra. Muitos de seus conceitos foram substituídos pelos ensinados por Deming, consubstanciados pelas palavras qualidade e produtividade, que pregam o aumento simultâneo dos níveis de qualidade e de produtividade com o objetivo de fornecer um produto melhor e mais barato.

Se esse movimento, lançado por Deming em 1950 no Japão, espalhou-se por todos os setores industriais do mundo, apenas sua parte mais charmosa, a da qualidade, atingiu as empresas de serviço. Talvez porque aumentar a produtividade é mais difícil, principalmente nas atividades de serviço, do que melhorar a qualidade.

Entretanto, acreditamos que as empresas de serviço deverão entrar em breve numa competição de preço. Em alguns ramos isso já está acontecendo, como no comércio, em especial no supermercado. Além disso, como os preços dos serviços, que já eram caros, subiram muito mais que a inflação desde o Plano Real, estão muito convidativos e, portanto, estão atraindo novas empresas. Empresas de serviço estrangeiras estão vindo para o Brasil e concorrendo, sim, em preço, nas áreas de fast food (McDonald's e Pizza Hut), de bancos (Santander, Lloyds Bank, HSBC, Caixa Geral de Depósitos de Portugal, Banco do Espírito Santo), de administração de shopping centers (a americana Compass administra o SP Market), de lavanderia (a americana Dry Clean cobra em São Paulo preços 40\% menores), de limpeza doméstica (Duraclean e MollyMaid, a maior empresa americana na área), de reparo de automóveis (Midas e O Mágico Amassado). Nem todas essas empresas vão ter preços menores, pois algumas anunciaram que vão oferecer serviços melhores pelo mesmo preço cobrado pelas nacionais, o que é também uma forma de competição em preço, porque também exige maior produtividade.

Assim, como aconteceu no passado da indústria, é previsível uma aguerrida competição em preço no setor de serviços, como já se verifica no comércio varejista e, principalmente, nos supermercados. Podem os empresários, portanto, preparar- 
se para guerra de preços e de promoções.

O consumidor não é tão exigente em relação ao preço de serviços como o é em relação ao preço de produtos - pesquisa e regateia muito mais nestes do que naqueles. Parece-nos que dificilmente preço deixará de ser critério qualificador para ser ganhador de pedido no setor de serviços. Mas, o consumidor brasileiro será muito mais restritivo: a maioria só qualificará as empresas cujos preços estejam num patamar mais baixo que a média, o que fará com que a média vá diminuindo gradativamente, pois, de um modo geral, considera caros os preços dos serviços.

\section{Terceiro impacto:}

\section{sobre a competição em produto para as empresas industriais}

Qualidade do produto e do serviço é uma das estratégias mais valorizadas atualmente e origina-se nas crescentes conscientização e exigência do comprador. É conseqüência da qualidade no processo de produção do produto ou do serviço.

A qualidade no processo industrial aumentou significativamente nos últimos anos. Em 1970, aceitavam-se até 10\% de peças defeituosas dentro de um lote; hoje, mede-se a qualidade do processo produtivo em número de peças defeituosas por milhão de peças fabricadas. A mudança de escala é o mais forte indicativo da melhoria da qualidade de processo. Portanto, para as empresas líderes em qualidade no processo, muito pouco há ainda a ganhar em termos de redução do número de defeitos.

Pela ótica do cliente e do consumidor, qualidade do produto ou do serviço passará a ser um critério qualificador e não mais ganhador de pedido - ele só comprará se a qualidade estiver acima do nível aceitável.

Assim, conclui Celso Contador (1998, p. 13):

Tanto pelo lado do produtor como do comprador, qualidade do produto deixará de ser um campo de competição para as empresas líderes em qualidade. As empresas seguidoras e as retardatárias ainda têm a percorrer um caminho, que poderá ser longo, até atingir um patamar próximo ao zero defeitos. 
Nos demais campos da competição do grupo produto indicados por Celso Contador, a empresa pode optar entre:

- competir em qualidade do projeto do produto ou do serviço, ou seja, pelas características e funçôes de seu desempenho e pela aparência exterior, inclusive de sua embalagem; ou

- competir em variedade de modelos do mesmo produto ou serviço; ou

- competir no lançamento de novos produtos ou serviços.

\section{Quarto impacto: sobre a competição em produto para as empresas de serviços}

A qualidade no processo industrial aumentou significativamente nos últimos anos, como foi demonstrado. Mas, a qualidade na maioria das empresas de serviços no Brasil deixa muito a desejar, até para o cliente menos exigente (uma inspeção séria da Vigilância Sanitária na cozinha dos restaurantes deixaria muito poucos abertos, inclusive os melhores de São Paulo). Assim, qualidade do serviço ainda está longe de deixar de ser um campo de competição no Brasil.

Porém, pela ótica do cliente, qualidade do serviço tenderá, a médio prazo, a ser um critério qualificador e não mais ganhador de pedido; ele só o adquirirá se a qualidade estiver acima do nível aceitável.

As características do serviço atendem às necessidades e anseios do cliente? Parece-nos que, numa pesquisa com os clientes, a maioria das respostas seria negativa. Portanto, campos de competição promissores são os relativos:

- à qualidade do projeto do serviço, ou seja, pelas características e funçôesde seu desempenho;

- à variedade de serviços; ou

- ao lançamento de novos serviços.

Quinto impacto: pequena diferença administrativa entre a empresa industrial e a 


\section{de serviços}

Por influência da Economia, que classificou os setores econômicos em extrativo, de transformação e de serviços, administrativamente tem-se tratado de forma distinta a empresa de cada setor: a empresa do agribusiness nada tem a ver com a empresa industrial; e a de serviços, muito menos ainda.

O paradigma do pensamento administrativo formal sempre foi a empresa industrial: Taylor, Fayol, Ford e os que os seguiram ocuparam-se exclusivamente dela. A empresa industrial, por possuir uma área produtora de bens, era mais complexa e desafiadora, o que estimulava a dedicação dos teóricos da Administração e motivava os empresários a aperfeiçoá-la. A atração exercida pela empresa industrial era tão grande que também sobre ela foram desenvolvidos os primeiros estudos da Escola de Relações Humanas e da Escola Comportamentalista. Como a maioria dos empresários da agricultura, do comércio e do serviço tinha pequena preocupação administrativa, havia pouco entusiasmo para a aplicação do conhecimento administrativo nas empresas desses setores.

A Administração atual não mais faz diferença entre a empresa industrial e as outras, porque se percebeu que também os serviços precisam ser produzidos. Nós vamos a um restaurante, tipicamente uma empresa de serviços, não apenas pelo bom atendimento mas, principalmente, pela qualidade da comida; vamos a um laboratório de análises clínicas pela qualidade dos resultados; não voltaremos a um hotel onde as roupas de cama e banho não estejam limpas, onde a cama não tenha sido bem arrumada. Ou seja, o serviço precisa ser bem produzido, quer na cozinha do restaurante, quer no laboratório, quer na lavanderia do hotel, quer pela camareira do hotel. Uma peça de teatro, um programa de televisão são produzidos; uma mulher bem vestida está produzida. A conclusão é clara: o serviço precisa ser produzido.

Portanto, às atividades de produção do serviço (às de retaguarda ou back room) podem e devem ser aplicadas todas as técnicas desenvolvidas originariamente para as atividades de produção de uma empresa industrial. Já para as atividades de contato com o cliente (as da linha de frente ou front office), essas técnicas não se aplicam. A distinção entre atividades de frente e de retaguarda, que está explícita na Teoria da Competitividade, tem grande importância para as empresas de serviços, que passam a dispor de um grande arsenal de armas industriais para aumentar 
sua competitividade. Essa distinção joga por terra o engano de que empresa de serviço é diferente da industrial: nas atividades de retaguarda, em que os serviços são produzidos, as empresas são muito parecidas.

Por outro lado, como afirmam Gianesi \& Corrêa (1997, p. 455-56), os serviços são um diferencial competitivo para as empresas de manufatura. Hoje, a empresa industrial não vende apenas bens, vende também serviços junto com os bens, formando um "pacote" produtos/serviços. Segundo esses autores,

As atividades de serviços exercem um papel importante no desempenho de outros setores da economia, principalmente o industrial, que pode ser sumariado em três categorias:

como diferencial competitivo - os serviços prestados pela empresa industrial ao cliente (como projeto, crédito, distribuição e assistência técnica) têm atuado no sentido de diferenciar o pacote produto/serviço que a empresa oferece ao mercado, gerando um diferencial competitivo em relação aos concorrentes;

como suporte às atividades de manufatura - muitas das funções dentro das empresas de manufatura são, na verdade, operações de serviços (como recursos humanos, manutenção e processamento de dados), que são fundamentais para o desempenho competitivo da empresa; e

como geradoras de lucro - muitas atividades de serviços de empresas de manufatura podem desenvolver-se a um ponto tal que ultrapassem a mera função de apoio, passando a constituir centro de lucros dentro das empresas. [A manutenção de elevadores feita pelo próprio fabricante serve como exemplo.]

Eis, portanto, a empresa industrial assemelhando-se à de serviço. Pode e deve, pois, nas atividades de front office, utilizar-se do arsenal de armas desenvolvido para a área de serviços.

Em suma, administrativamente, há pequena diferença entre empresa industrial e empresa de serviços, desde que se distingam as atividades em de retaguarda e de frente. Em outras palavras, quase sempre, na área industrial, há um serviço agregado a um produto e, na área de serviço, um produto agregado a um serviço. Produtos e serviços são considerados componentes de um pacote, em que pode haver predominância de um ou de outro.

ABSTRACT: The impact that the post-formal thought caused upon society is analyzed under the scope of fields and weapons of competition (approaching only price and quality) as well as considering different competitive level of companies in relation 
to industries and points of view of companies and consumers. Five impacts, which are considered to be the most important ones, are focused in this context.
KEY WORDS: post-formal thought, competition fields and guns, companies, consumer, industries.

\section{REFERÊNCIAS BIBLIOGRÁFICAS}

Albrecht, Karl. [1997]. A única coisa que importa. São Paulo, Pioneira.

Albrecht, Karl. [1994] Revolução nos serviços. São Paulo, Pioneira.

Chiavenato, Idalberto. [1983] Introdução à Teoria Geral da Administração. 3. ed. São Paulo, McGraw-Hill.

Contador, J. Celso. [1996] Modelo para aumentar a competitividade industrial. São Paulo, Edgard Blücher .

Contador, J. Celso. [1998] A empresa do futuro. São Paulo, Universidade Paulista (UNIP). Mimeo.

Contador, J. Luiz. [1999] Abordagens da administração na organização. Guaratinguetá, Universidade Estadual Paulista (UNESP). Mimeo.

CorrêA, Henrique \& Gianesi, Irineu. [1997] Estratégia de operações. In: CoNTADOr, J. Celso. Gestão de operações. São Paulo, Edgard Blücher.

Gianesi, Irineu \& CorrêA, Henrique. [1997] Serviços. In: Contador, J. Celso. Gestão de operaçôes. São Paulo, Edgard Blücher.

Horovitz, Jacques. [1993] Qualidade de serviço. São Paulo, Pioneira.

PORTER, Michael. [1989] Estratégia competitiva. Rio de Janeiro, Campus. 
E
C
C
O
S
R
E
V.
C
I
E
N
T.
n. 1
v. 1

dez.
1999

62 